\title{
Accumulation of class-III type of boiling stable Peroxidases in response to plant growth hormone $\mathrm{ABA}$ in Triticum aestivum cultivars
}

\author{
Arun Dev Sharma, Gurmeen Rakhra, Shweta Mehta, Shubhneet Mamik
}

\begin{abstract}
Abscisic acid (ABA) is a key plant growth and stress hormone involved in many biological processes. It has been shown to be involved in Reactive Oxygen Species (ROS) generation. Class-III Peroxidases (PODs) are known to maintain oxidative stress induced-ROS at sublethal levels in plants under abiotic stress conditions, but, studies documenting how ABA regulates boiling stable class-III PODs are still a matter of conjuncture. In this study, the ABA-induced changes on ROS and ROS scavenging class III boiling stable POD were studied in the embryos of different cultivars of wheat. Simultaneous analysis of ROS contents, activities of ROS-scavenging class- III boiling stable POD enzymes gave an integrative view of physiological state and detoxifying potential under conditions of sensitivity and tolerance. Indices of oxidative stress viz., superoxide radical and $\mathrm{H}_{2} \mathrm{O}_{2}$ content increased under ABA treatment in a genotype dependent manner. It was observed that cultivars: PBW 550, HD 2967 and PBW 621 have more efficient mechanism to scavenge ROS species as shown by increase in BsPOD activity accompanied by enhanced expression of boiling stable POD isoenzymes. Based on results it can be inferred that embryos of cvs. PBW 550, HD 2967 and PBW 621 have more capacity to perform biological antioxidative reactions to combat $\mathrm{ABA}$-induced oxidative stress.
\end{abstract}

Key words: Boling stable proteins, Class-III Peroxidase, isoenzymes, wheat.

Received: 28 October 2013 / Accepted: 4 December 2013 / Published online: 1 January 2014

(C) Horizon e-Publishing Group

CITATION

Sharma, A.D., Rakhra, G., Mehta, S., \& Mamik, S. (2014). Accumulation of class-III type of boiling stable Peroxidases in response to plant growth hormone ABA in Triticum aestivum cultivars. Plant Sci. Today, 1(1), 3-9. http://dx.doi.org/10.14719/pst.2014.1.1.6

Arun Dev Sharma $(\otimes)$, Gurmeen Rakhra, Shweta Mehta, \& Shubhneet Mamik

PG Dept of Biotechnology, Lyallpur Khalsa College, GT Road, Jallandhar-144001, Punjab, India. Email:arundevsharma@hotmail.com

\section{Introduction}

The phytohormone abscisic acid (ABA) regulated various growth and developmental related processes in plants (Shinozaki \& Yamaguchi-Shinozaki, 2007). Besides that, ABA mainly involved in regulating various adaptive responses to various adverse abiotic conditions like drought, salt, high temperature and cold. Both ABA dependent and independent pathways contributing to water stress adaptation have been documented (Shinozaki \& Yamaguchi-Shinozaki, 2007). A growing body of evidence indicated that $A B A$ is associated with oxidative stress in plant cells and can cause the generation of Reactive Oxygen Species (ROS) such as such as $\mathrm{H}_{2} \mathrm{O}_{2}$ (hydrogen peroxide), $\mathrm{O}_{2 .-}$ (superoxide) and $\mathrm{OH}$ (hydroxyl) radicals in a tissue dependent manner (Gao et al., 2008). Under optimal conditions ROS are inevitable from the essential aerobic metabolisms including chloroplast, mitochondrial, per-oxidation of membrane lipids, and plasma membrane linked electron transport systems (Bi et al., 2009). Besides dangerous cytotoxic molecules, ROS have been shown to act as second messengers involved in the various stress signal transduction pathways including control and regulation of biological processes like cycle and programmed cell death and hormone signalling (Graper \& Dolan, 2006). However, excessive ROS synthesis often leads to oxidative stress, which damages plants by oxidizing photosynthetic pigments, membrane lipids, proteins and nucleic acids (Mittler, 2002; Baruah et al., 2009). Oxidative stress arises due to imbalance between generation and elimination of ROS which can lead to changes in bio-membrane permeability and membrane leakage. These studies suggest us the dual role of ROS in plant biology as dangerous molecules and key regulators of growth, and defence pathways. Earlier studies have documented that ABA-induced accumulation of ROS plays an important role in the ABA signal transduction pathways associated with the induction of antioxidant defence systems (Jiang \& Zhang, 2002; Hu et al., 2005). Plants have ability to sense ROS and reprogramme their gene expression in response to changing conditions in their environment. Many microarray studies involving mutants and antisense lines that lack ROS-scavenging enzymes revealed that ROS act as signalling molecules involved in 
the expression of a large number of genes and biological processes (Miller et al., 2008). Among all antioxidative enzymes (like SOD, CAT, GST, GR, MDAR, DHAR, GPx) involved in mitigating the effect of oxidative stress, classIII Peroxidase (PODs) are the major antioxidative enzymes grouped in a super-family utilizing guaiacol as electron donor, located in cytosol, cell wall and involved in decomposition of $\mathrm{H}_{2} \mathrm{O}_{2}$ through the oxidation of phenolic compounds. Broadly, peroxidases (Prx) have been defined in three different groups. Class-I, mainly included ascorbate Prx, cytochrome-c peroxidases (CcPs), while class-II, encoded exclusively by fungus, are divided into manganese Prxs and lignin Prxs, while class-III contains all the secretary plant Prxs (PODs) (for review see Cosio \& Dunand, 2009). Several roles have been attributed to plant class-III Prxs in response to biotic and abiotic stresses such as in the modification of cell wall like suberin polymerization, cross-linking of structural non-enzymatic proteins, and ability to cleave cell wall polysaccharides, leaf expansion, fruit growth, germination, nodulation (Cosio \& Dunand, 2009). They may have diverse roles possibly due to large number of isoforms (isoenzymes). The quantitative and qualitative changes in the expression of antioxidant enzymes are often related to the levels of resistance to water stress. Some studies indicated that activities of antioxidant enzymes are correlated with plant tolerance to abiotic stress (Ozkur et al., 2009; Wang et al., 2009).

Earlier it was demonstrated that many water-stress inducible- proteins (e.g. HSPs, LEAs) are highly hydrophilic and remain soluble even after boiling, thereafter has been termed as "boiling stable proteins" (BSPs) (Jacobsen \& Shaw, 1989). Many proteins which were detected in total protein extracts are lost after boiling the extracts (Pelah et al., 1995). Earlier research also indicated that hydrophilins represent less than $0.2 \%$ of the total protein of a given genome, however, it represents the most significant part of proteome in regulating tolerance to abiotic stresses (for review see BATTAGLIA et al 2008). Hence, to better elucidate the role of these boiling stable proteins (BSPs), it is a prerequisite to examine their expression not only under water stress, but also after boiling of extracts. Moreover, the role of boiling stable class-III type of peroxidases antioxidant enzymes PODs) under $A B A$ treatment is not well documented. As ABA is involved in water stress response and it is well established that water stress tolerance is dependent on multiple genes, so antioxidant enzymes constitute an important group involved in ABA-regulated water stress tolerance. Therefore, in the present study, we have analyzed the effect of $\mathrm{ABA}$ on biochemical activity and isoenzyme expression profile of boiling stable (hydrophilic) Class-III type of Prx (POD) along with ROS contents in the embryos of different wheat cultivars. Analysis of isoforms of boiling stable POD coupled with biochemical analysis will provide new insights into ABA-induced oxidative stress. Wheat is one of the most important crops in arid and semi arid areas worldwide and is sensitive to drought and temperature stress. In order to facilitate the detection of BSPs, heat stable (HS) fractions that resists coagulation upon heating at $100^{\circ} \mathrm{C}$ were focussed.

\section{Material and methods}

\section{Seed germination and growth conditions}

The seeds of Triticum aestivum L. cvs., PBW 621, HD 2967, PBW 343, PBW 550, HD 2894 (Irrigated) and PBW 527 (Rain-fed), which differ in their cultivation conditions (Table 1) (Lal, 2010; IARI, 2013), were obtained from PAU Ludiahana, Punjab, India. The different cultivars were selected as per their crop yield capacities. Washed grains were surface sterilized with $1 \%(\mathrm{w} / \mathrm{v})$ mercuric chloride followed by $70 \%$ ethanol. Seeds were thoroughly rinsed with deionized water and imbibed for $6 \mathrm{~h}$. After imbibation, seeds were placed in petriplates containing sterile filter sheets, and incubated $25 \pm 1^{\circ} \mathrm{C}$ in a seed germinator for $12 \mathrm{~h}$. For ABA treatment, seeds after $12 \mathrm{~h}$ of germination, were irrigated with $A B A$ solution $(100 \mu \mathrm{m})$ as described previously (Sharma et al., 2006). The Control plates were irrigated with deionized water. The plates were further incubated at $25 \pm 1^{\circ} \mathrm{C}$ in a seed germinator for $18 \mathrm{~h}$. Each treatment was repeated three times independently of each other and each replicate included 100 seeds (i.e. 300 seeds per treatment). For biochemical analysis, embryos from each replicate independently of other replicate were combined and used for further studies. Embryos were stored immediately in liquid nitrogen until further analysis. Parts of these tissues were weighed to obtain the fresh weight (FW). The dry weight (DW) was obtained after drying the different tissues at $75^{\circ} \mathrm{C}$ till constant weight. TWC was calculated from given equation: $\mathrm{TWC}=\mathrm{FW}-\mathrm{DW} / \mathrm{DW}$.

\section{Extraction of Boiling Stable Proteins}

The boiling stable proteins were extracted as described previously [Sharma et al., 2006; Sharma et al., 2012]. Briefly, tissues were homogenized with chilled mortar and pestle in extraction buffer [50mM Tris buffer ( $\mathrm{pH} 7.0)]$. Crude extracts were centrifuged at $10,000 \mathrm{~g}$ for $10 \mathrm{~min}$. The total extract as obtained was boiled for $15 \mathrm{~min}$ in order to get boiling stable protein fractions. The total soluble protein content in the supernatant was determined according to Lowry et al., 1951 using BSA as a standard.

\section{BsPOD activity analysis}

The BsPOD activity was measured according to the method described by Chance \& Mahley (1955) with some modifications. The mixture contained $50 \mathrm{mM}(\mathrm{pH} 7.0)$, $10 \mathrm{mM}$ guaiacol and $5 \mathrm{mM} \mathrm{H} \mathrm{H}_{2} \mathrm{O}_{2}$. To this mixture an equivalent of $120 \mu \mathrm{g}$ of protein was added making the total volume to $1 \mathrm{ml}$. The increase in absorbance was measured at $470 \mathrm{~nm}$ at intervals of 30 secs. The activity was 
calculated as per min per milligram of tetraguaiacol production by using the extinction coefficient for tetraguaiacol of $26 \mathrm{mM}^{-1} \mathrm{~cm}^{-1}$.

Table 1: Cultivars used in this study

\begin{tabular}{|c|c|c|c|}
\hline $\begin{array}{c}\text { Cultivation } \\
\text { conditions / nature } \\
\text { of genotype }\end{array}$ & Genotype & $\begin{array}{c}\text { Year of } \\
\text { release }\end{array}$ & $\begin{array}{c}\text { Average } \\
\text { yield } \\
\text { (q/acre) }\end{array}$ \\
\hline Tsi & PBW 343 & 1995 & 19.0 \\
\hline Tsi & PBW 550 & 2007 & 20.8 \\
\hline Ts, Rf & PBW 527 & 2007 & 13.7 \\
\hline Tsi & HD 2894 & 2008 & 20.0 \\
\hline Tsi & HD 2967 & 2010 & 20.1 \\
\hline Tsi & PBW 621 & 2011 & 21.1 \\
\hline
\end{tabular}

Tsi: timely sown, irrigated; TsRf: timely sown, rain-fed. Information retrieved from Lal (2010) and IARI (2013).

\section{In-gel BSPOD activity (isoenzyme) analysis}

Boling stable proteins were extracted as described above. For in-gel activity analysis, the proteins $(240 \mu \mathrm{g})$ were separated by a non-denaturing $12 \%$ polyacrylamide gel electrophoresis as described in Sambrook et al. (1989). When electrophoresis was complete, the gel was washed three times in $50 \mathrm{mM}$ sodium acetate buffer ( $\mathrm{pH} 5.0$ ). Peroxidase activity was visualized by incubating the gel in $50 \mathrm{ml}$ of solution having $50 \mathrm{mM}$ sodium acetate buffer $\mathrm{pH}$ $5.0), 330 \mathrm{ul}$ of guaiacol $(9 \mathrm{M})$ and $1.5 \mathrm{ml}$ of $6.6 \% \mathrm{H}_{2} \mathrm{O}_{2}$. The gel was incubated at room temperature in dark until reddish-brown bands appeared. The gel was washed in distilled water and used for further analysis. Relative expression of isoenzymes was quantified by Ultraquant software 13.3.26 of gel documentation system (Omega Lum USA)

\section{Estimation of Hydrogen Peroxide content}

The $\mathrm{H}_{2} \mathrm{O}_{2}$ content was measured by the method described by Chakrabarty et al. (2009). The reaction mixture contained $0.5 \mathrm{ml}$ of Tris-HCL buffer $\mathrm{pH} 7.0,0.5 \mathrm{ml}$ of $0.1 \%$ Trichloroacetic acid (TCA), $120 \mu \mathrm{g}$ of protein, $2 \mathrm{ml}$ of $1 \mathrm{M} \mathrm{KI}$. After $1 \mathrm{hr}$ of reaction in dark, the absorbance was measured at $390 \mathrm{~nm}$. The amount of hydrogen peroxide $(\mu \mathrm{M} / \mathrm{gFW})$ was calculated using a standard curve prepared with known concentration of $\mathrm{H}_{2} \mathrm{O}_{2}$.

\section{Estimation of Superoxide anion content}

The superoxide anion content was measured as described by Navari-Lzzo et al. (1999) with some modifications. The reaction mixture contained of $50 \mathrm{mM}$ Tris-HCL buffer, $0.05 \% \mathrm{NBT}$ and $10 \mathrm{mM} \mathrm{NaN}_{3}$ and the enzyme extract equivalent to $120 \mu \mathrm{g}$ of protein. After $5 \mathrm{~min}$ incubation in the dark, the mixture was heated at $85^{\circ} \mathrm{C}$ for $15 \mathrm{~min}$. The samples were cooled and the absorbance was measured at $580 \mathrm{~nm}$. The superoxide anion content $(\mu \mathrm{M} / \mathrm{gFW})$ was calculated by preparing a standard curve with known concentration of NBT.

\section{Lipid peroxidation}

Lipid peroxidation was estimated by the level of malondialdehyde (MDA) production. The level of lipid peroxidation products was estimated following the method of Heath \& Packer (1968). Fresh samples $(120 \mu \mathrm{g})$ were mixed with $0.25 \%$ thiobarbituric acid (TBA) in $10 \%$ TCA. The mixture was heated at $95^{\circ} \mathrm{C}$ for $30 \mathrm{~min}$ and then quickly cooled in an ice bath and centrifuged at $10000 \times \mathrm{g}$ for $10 \mathrm{~min}$. The absorbance of the supernatant was read at $532 \mathrm{~nm}$ for the spectrophotometric determination of MDA and correction for unspecific turbidity was done by subtracting the absorbance of the same at $600 \mathrm{~nm}$. MDA concentrations were calculated by means of extinction coefficient of $156 \mathrm{mM}^{-1} \mathrm{~cm}^{-1}$ and the following formula: MDA $(\mu \mathrm{mol} / \mathrm{gFW})=[(\mathrm{A} 532-\mathrm{A} 600) / 156] \times 103 \times$ dilution factor.

\section{Statistical analysis}

StatView ANOVA program (Sidel, 1986) was used for statistical analysis of the data. Values were compared using one-way analysis of variance and student's t-test for differences between pairs of data if the ANOVA (LSD 0.05) revealed significance. Means were tested by LSD at P 0.05 level (LSD 0.05).

\section{Results and discussion}

ABA-induced changes in fresh weight (FW), dry weight (DW) and Tissue water content (TWC)

In relation to growth, among all the cultivars studied, $c v$. PBW 343 showed a sharp decrease in FW after the imposition of ABA treatment. However, no significant change was observed in other cultivars (Fig. 1a). Further, our results showed that imposition of ABA treatment resulted in a very significant reduction in dry matter (DW) of $c v s$. PBW 550 and PBW 343 (Fig. 1b), probably because cell expansion was not accompanied by cell division or it might be attributed to the decreased synthesis of new materials or decreased synthetic activity associated with cell division (Sharma et al., 2006). Further ABA-treatment decreased the TWC in $c v .550$, however, cvs. 2894, 2967 and 343 showed a substantial increase in TWC after ABA treatment. In contrast, $\mathrm{ABA}$ treatment did not alter any change in TWC in cvs. 527, and 621 (Fig. 1c). Taken together, it can be speculated that this kind of response may be a sort of protection given by osmolytes under oxidative stress. As indicated earlier Pinheiro et al. (2004) also observed no change in tissue water content upon drought stress. Same authors demonstrated that this response is associated with protection given by assimilates 
mainly fructose, glucose and sucrose whose levels doubles under water deficits.
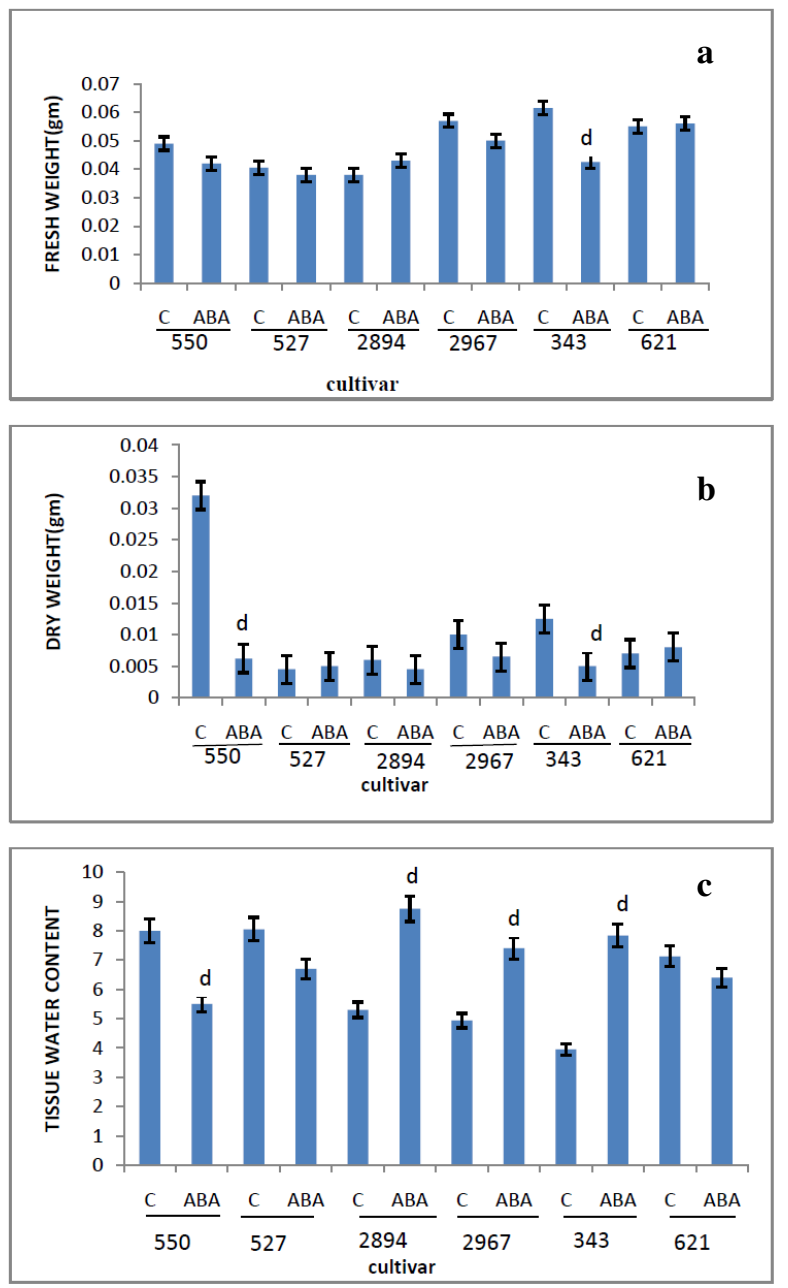

Fig. 1. Effect of ABA treatment on fresh weight (FW) (a), dry weight (DW) (b) and tissue water content (TWC) (c) of embryos of different cultivars of Triticum aestivum. Data shown are average \pm SD of three replicates. $d$ represents significantly different treatments with respect to non-ABA control $\mathrm{p} \leq 0.5$.

Changes in Reactive Oxygen Species (ROS), hydrogen peroxide $\left(\mathrm{H}_{2} \mathrm{O}_{2}\right)$ and superoxide $\left(\mathrm{O}_{2} \cdot-\right)$ content

Exposure to ABA caused significant increase in $\mathrm{H}_{2} \mathrm{O}_{2}$ levels in $c V .2967$ (Fig. 2a). O 2.- content increased substantially in cvs. 527, 2967 and 621 (Fig. 2b). The enhanced ROS production under oxidative stress may pose threat to cells, but it is also possible that ROS serve signal molecules to activate antioxidant stress responses and defence pathways ( $\mathrm{Li} \& \mathrm{Yi}, 2012$ ). It is well-documented that cellular level of $\mathrm{H}_{2} \mathrm{O}_{2}$ stays high in relation to oxidative stress situations and plays a central role in responses to both abiotic and biotic stresses in plants. Up to certain concentration $\left(10^{2}-2 \times 10^{5} \mu \mathrm{M}\right)$ this molecule seems to be a "master hormone" that controls a variety of stress responses and physiological adjustments, including the
ROS/hormonal homeostasis in the cell (Shigeoka et al., 2002). Thus ABA-induced ROS can be taken as indicators of stress and as secondary molecules involved in oxidative stress response signal pathways. However, cvs. 2894 and 343 depicted a sharp decrease in ROS levels upon exposure to ABA (Fig. 2). All these observations suggest ABA-regulated control of ROS production in a genotype dependent manner. Interestingly only in $c v$. 527, a sharp increase in $\mathrm{O}_{2}$ - content accompanied by decrease in $\mathrm{H}_{2} \mathrm{O}_{2}$ levels was observed. No specific generalization for this fact could be made out at this point.
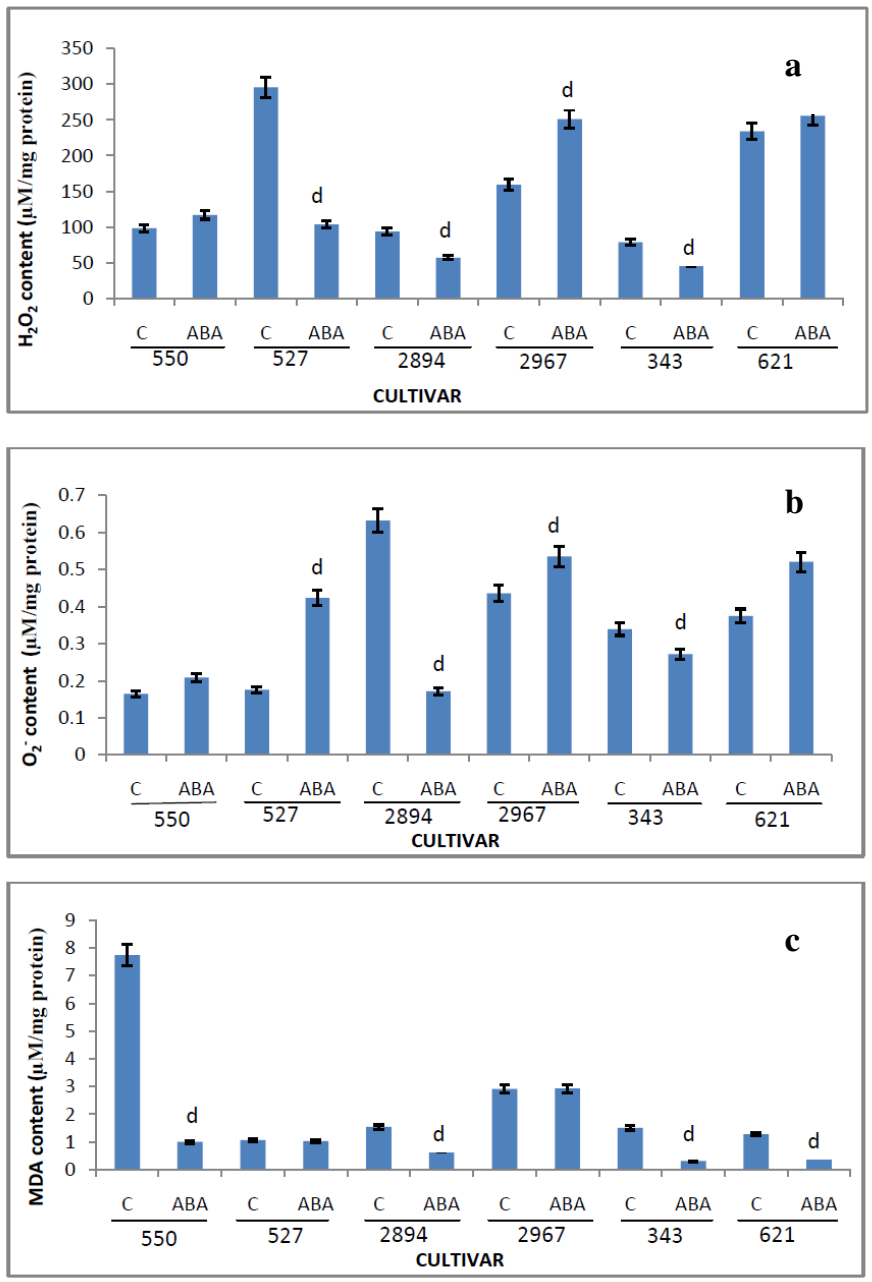

Fig. 2. Effect of $A B A$ treatment on $\mathrm{H}_{2} \mathrm{O}_{2}$ (a), 02.- content (b), and MDA content (c) content of embryos of different cultivars of Triticum aestivum. Data shown are average \pm SD of three replicates. $d$ represents significantly different treatments with respect to non-ABA control $p \leq 0.5$.

\section{Changes in lipid peroxidation (MDA)}

ROS $\left(\mathrm{O}_{2 .-}\right.$ and $\left.\mathrm{H}_{2} \mathrm{O}_{2}\right)$ can initiate lipid peroxidation which finally leads to disintegration of bio-membranes. Hence ROS scavenging is the right protection mechanism to preserve membrane integrity. Malondialdehyde (MDA) is generally considered as sensitive marker to asses oxidative stress induced membrane peroxidation (Goel \& 
Sheron, 2003). The level of lipid peroxidation in ABAtreated embryos was measured as the content of MDA, as it is a product of membrane lipid peroxidation. Interestingly, in this study, after the imposition of ABA, cvs. 550 and 621 showed a sharp decrease in MDA content, suggesting that ABA-induced boiling stable PODs provided sufficient protection against oxidative stress. However, ABA had no marked effect on MDA in cvs. 527 and 2967 (Fig. 2c). This may be attributed to overall increase in lipid or water soluble antioxidant metabolites and other $\mathrm{H}_{2} \mathrm{O}_{2}$ detoxifying antioxidant enzyme activities. Notably, $c v .343$ and $c v .2894$ also showed a sharp decrease in MDA values, suggesting different $A B A$ dependent regulatory pathways controlling lipid peroxidation in a genotype dependent manner. Earlier studies documented that, besides, enzymatic antioxidant enzymes, non-enzymatic metabolites like ascorbate and glutathione pool in addition to be involved in ROS scavenging has along with alphatocopherol been reported to be involved in suppression of peroxidation of membrane lipids by reducing the MDA content thus aiding protection to the integrity of the biomembranes (Gill \& Tuteja, 2010). Taken together, it can be speculated that embryos are better protected against ABAinduced oxidative stress, as indicated by low levels of MDA, through different regulatory pathways in a cultivar dependent manner.

ABA-induced changes in boiling stable POD activity and isoenzymes

Previously, it has reported that embryo germination, growth, and other biochemical processes can be affected in seeds that are subjected to environmental cues (Sharma et al., 2006). These changes can affect other metabolic activities, particularly the alternation in protein metabolism that plays an important role in embryo germination and seed development (Fincher, 1989). However, the exact role of boiling stable Prx class III antioxidant enzymes (PODs) under ABA treatment is still not well documented. So in order to gain further insight into the biochemical role of boiling stable class III PODs (BsPODs) we studied the effect of ABA, a hormone known to enhance abiotic stress tolerance, on the expression of BsPODs in different cultivars of wheat. To control the steady-state ROS levels, Class III PODs are important enzymes of the antioxidative system for the reduction of $\mathrm{H}_{2} \mathrm{O}_{2}$ to water (Cosio \& Dunand, 2009; Miller et al., 2008). The changes in BsPOD activities in embryos of different wheat cultivars are shown in Fig. 3A.

Among all the cultivars studied, as compared to control, imposition of $\mathrm{ABA}$ treatment significantly induced the BsPOD activity in $c v .550$ (2.0-fold), 2967 (1.5-fold) and 621 (2.2-fold). This study also supports the idea that higher BsPOD activity being detected in embryos under ABA treatment, may be ascribed to high cellular ROS levels. So enhanced BsPOD activity associated with ROS generation, suggesting an induction of antioxidants defences regulated by ROS controlled signalling pathways.
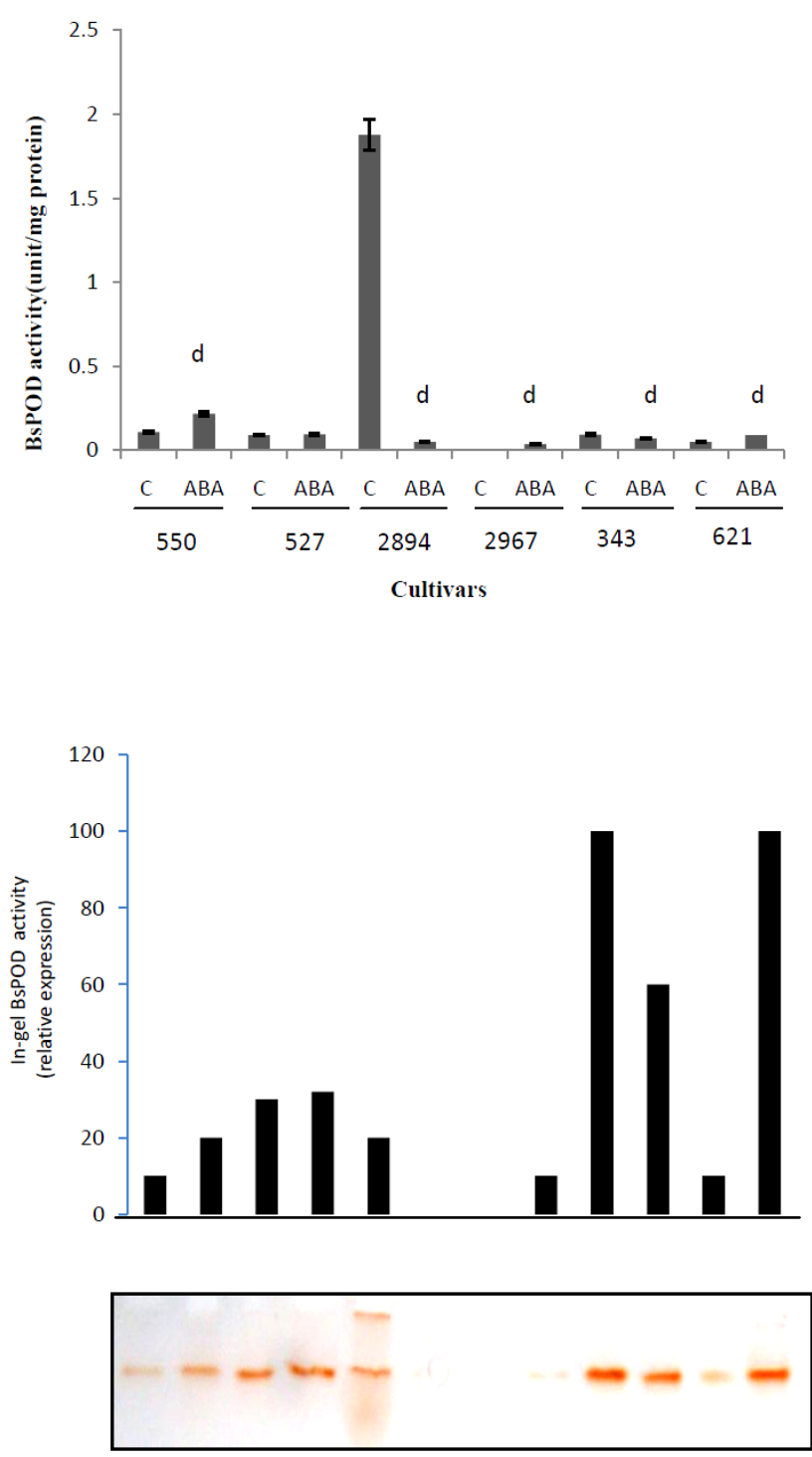

$$
\begin{gathered}
\frac{\mathrm{C} \quad \mathrm{ABA}}{550} \frac{\mathrm{C} \quad \mathrm{ABA}}{527} \frac{\mathrm{C} \quad \mathrm{ABA}}{2894} \frac{\mathrm{C} A \mathrm{ABA}}{2967} \frac{\mathrm{C} \quad \mathrm{ABA}}{343} \frac{\mathrm{C} \quad \mathrm{ABA}}{621} \\
\text { Cultivars }
\end{gathered}
$$

Fig. 3. ABA-induced changes in BsPOD specific activity (a) and in-gel BsPOD activity/isoenzyme analysis (b) of boiling stable Class-III peroxidases in different cultivars of Triticum aestivum. Bar graphs as shown in the top of Panel $b$, indicates relative band intensities, which were determined using Ultraquant software of Gel Visualization,

Documentation and Analysis system (Omega-Lum, USA).

Higher total BsPOD activity under ABA treatment could also be result from a combination of changes in transcription and translation, higher stability of transcript or protein and change in the enzyme active state. On the other hand cvs. 2894 and 343 showed a sharp decline in BsPOD activity after ABA treatment, whereas as no change 
was observed in $c v$. 527, indicating genotype specific regulation of BsPrxs. The reduction of BsPOD activity in cvs. 2894 and 343, is supposedly due to the inhibition of enzyme synthesis or change in the assembly of enzyme subunits or inactivation of enzyme protein due to ROSinduced oxidative stress conditions. It may also be associated with degradation caused by induced peroxisomal proteases or may be due to the photoinactivation of the enzyme. Further, in cvs. 2967 and 621, ROS content increased accompanied by a sharp decrease or unchanged MDA levels. Based on these observations it can be postulated that these cultivars, by virtue of having high BsPOD activity, were able to maintain the stability of bio-membranes by controlling lipid peroxidation. Pattern of boiling stable POD isoenzymes (in-gel BsPOD activity) are shown is Fig. 3B. After native-PAGE analysis, one main boiling stable POD isoenzyme was detected. Curiously enough, like BsPOD activities, imposition of ABA treatment drastically provoked the relative expression of BsPOD isoenzyme in cvs. 550, 2967 and 621, thereby indicates that these genotypes, which have high yielding capacity as shown in Table 1 , have better scavenging capacity and higher tolerance to oxidative stress than other cultivars like 2894 and 343. The relative expression decreased in cvs. 2894 and 343, this may be related to low ROS scavenging capacity of these cultivars to remove ROS under ABA treatment. Taken together accumulative evidences have further shown that different regulatory pathways are involved to control expression of BsPOD activity and isoenzymes (in-gel BsPOD activity) under ABA treatment. Moreover, the relative expression of isoenzymes was well correlated with the changes as observed in solution biochemically. Enhanced class-III BsPOD activities accompanied by isoenzyme expression may be involved in defense mechanism in embryos germination against ABA-induced oxidative stress during germination. Increased in-gel BsPOD activities of cvs. 550, 2967,621 may be indication of the cellular evaluated ROS, since the amount of POD enzyme present in aerobic cells is directly related to the oxidative state of the cell (Apel \& Hurt, 2004). In the earlier studies, the increase in the activities of antioxidant enzymes by ABA application was reported in different cultivars of wheat (Bano et al., 2012). So as an adaptive enzyme in antioxidant system, Class-III BsPOD play an important role in protecting membrane lipids from peroxidation and in reducing the cell damage being caused by ABA-induced oxidative stress in embryos.

\section{Conclusion}

To conclude, this study provided a particular insight into the changes in ROS production and boiling stable antioxidant POD activities in embryos under ABA-induced oxidative stress. Higher BsPOD activity accompanied by isoenzyme expression confirmed their role for survival under ABA-induced oxidative stress. They are hydrophilic and remain soluble upon boiling like LEA-type proteins, representing a new class of plant proteins involved in the plant's responses to abiotic stresses. Our study suggests that ABA-induced ROS and increased antioxidant enzyme capacity. ABA-induced ROS such as $\mathrm{O}_{2}$-- and $\mathrm{H}_{2} \mathrm{O}_{2}$, are able to stimulate antioxidant enzyme expression, thus providing adaptation to stress by modulating antioxidant defence system. Results described here confirmed enhanced BsPOD activities during oxidative stress were thereby dependent on plant genotype. The study further suggest protective role played by boiling stable Class-III BsPOD under ABA-induced oxidative stress and their significance as the basis of tolerance shown by high yielding genotypes like 550, 2967 and 621. These results can be utilized as biochemical marker while breeding oxidative stress tolerant high yielding crops in arid regions. More studies are required to see whether this increase due to gene transcription, and de novo synthesis of protein or are due to posttranslational modification of existing protein. Further analysis of the regulation of gene expression in these enzymes should elucidate the mechanism of different oxidative stress tolerances.

\section{Acknowledgements}

A.D. Sharma would like to thank UGC, Govt. of India for providing financial assistance for the present study.

\section{References}

Apel, K., \& Hirt, H. (2004). Reactive oxygen species: metabolism, oxidative stress, and signal transduction. Annu Rev Plant Biol, 55, 373-399. http://dx.doi.org/10.1146/annurev.arplant.55.031903.141701

Bano, A., Ullah, F., \& Nosheen, A. (2012). Role of Abscisic acid and drought stress on the activities of antioxidant enzymes in wheat. Plant Soil Environ, 58, 181-185.

Baruah A., Simkova K., Apek K., \& Laloi C. (2009). Arabidopsis mutants reveal multiple singlet oxygen signalling pathway involved in stress response and development. Plant Biol, 70, 547-563.

Battaglia, M., Olvera-Carrillo, Y., Garciarrubio, A., Campos, F., \& Covarrubias, A., A. (2008). The enigmatic LEA proteins and other hydrophilins. Plant Physiol, 148, 6-24. http://dx.doi.org/10.1104/pp.108.120725

Bi, Y., H., Chen, W., L., Zhang, W., N., Zhou, Q., Yun, L., J., \& Xing, D. (2009). Production of reactive oxygen species, impairment of photosynthetic function and dynamic changes in mitochondria are early events in cadmium induced cell death in Arabidopsis thaliana. Biol Cell, 101, 629643. http://dx.doi.org/10.1042/BC20090015

Chakrabarty, D., Verma, A., K., \& Datta, S., K. (2009). Oxidative stress and antioxidant activity as the bassenescence in Hemerocallis (day lily) flowers. J Hortic Forestry, 1, 113-119.

Chance, B., \& Maehly, A. (1955). Assay of catalases and peroxidases. Methods Enzymol, 2, 764-775. http://dx.doi.org/10.1016/S00766879(55)02300-8

Cosio, C., \& Dunand, C. (2010). Transcriptome analysis of various flower and silique development stages indicates a set of class III peroxidase genes potentially involved in pod shattering in Arabidopsis thaliana. BMC Genomics, 11, 528. http://dx.doi.org/10.1186/1471-2164-11-528

Fincher, G., B. (1989). Molecular and cellular biology association with endosperm mobilization in germination cereal grains. Annu Rev Plant 
Physiol Plant Mol Biol, 40, 305-346. http://dx.doi.org/10.1146/annurev.pp.40.060189.001513

Gao, C., J., Xing, D., Li, L., \& Zhang, L., R. (2008). Implication of reactive oxygen species and mitochondrial dysfunction in the early stages of plant programmed cell death induced by ultraviolet-C overexposure. Planta, 227, 755-767. http://dx.doi.org/10.1007/s00425-007-0654-4

Gill, S., S., \& Tuteja, N. (2010). Reactive oxygen species and antioxidant machinery in abiotic stress tolerance in crop plants. Plant Physiol Biochem, 48, 909-930. http://dx.doi.org/10.1016/j.plaphy.2010.08.016

Goel, A., \& Sheoran, I., S. (2003). Lipid peroxidation and peroxide scavenging enzymes in cotton seeds under natural ageing. Biol Plant, 46, 429-434. http://dx.doi.org/10.1023/A:1024398724076

Graper, C., \& Dolan, L. (2006). Control of plant development by Reactive Oxygen Species. Plant Physiol, 141, 341-345. http://dx.doi.org/10.1104/pp.106.079079

Heath, R., L., \& Packer, L. (1968). Photoperoxidation in isolated chloroplasts. I-Kinetics and stoichiometry of fatty acid peroxidation. Arch Biochem Biophy 125, 189-198. http://dx.doi.org/10.1016/00039861(68)90654-1

Hu, X., Jiang, M., Zhang, A., \& Lu, J. (2005). Abscisic acid-induced apoplastic $\mathrm{H}_{2} \mathrm{O}_{2}$ accumulation up-regulates the activities of chloroplastic and cytosolic antioxidant enzymes in maize leaves. Planta, 223, 57-68. http://dx.doi.org/10.1007/s00425-005-0068-0

IARI (2013). Retrieved from http:// www.iari.res.in

Jacobsen, J., V., \& Shaw, D., C. (1989). Heat-stable proteins and Abscisic acid action in barley aleurone cells. Plant Physiol, 91, 1520-1526. http://dx.doi.org/10.1104/pp.91.4.1520

Jiang, M., \& Zhang, J. (2002). Water stress-induced abscisic acid accumulation triggers the increased generation of reactive oxygen species and upregulates the activities of antioxidant enzymes in maize leaves. J Exp Bot, 53, 2401-2410. http://dx.doi.org/10.1093/jxb/erf090

Lal, S. (2010). Guidelines for selection of improved varieties/hybrids of rice, wheat and pulses for NFSM states. Department of Agriculture and Cooperation Ministry of Agriculture Government of India Krishi Bhawan, New Delhi-110001.

Li, L., \& Yi, H. (2012). Effect of sulfur dioxide on ROS production, gene expression and antioxidant enzyme activity in Arabidopsis plants. Plant Physiol Biochem, 58, 46-53. http://dx.doi.org/10.1016/j.plaphy.2012.06.009

Lowry, O., H., Rosebrough, N. J., Farr, A., L., \& Randall, R., J. (1951). Protein measurement with the Folin phenol reagent. J Biol Chem, 193, 265-275.

Miller, G., Shulaev, V., \& Mittler, R. (2008). Reactive oxygen signalling and abiotic stress. Plant Physiol, 133, 481-489. http://dx.doi.org/10.1111/j.1399-3054.2008.01090.x

Mittler, R. (2002). Oxidative stress, antioxidants and stress tolerance. Trends Plant Sci, 7, 405-410. http://dx.doi.org/10.1016/S13601385(02)02312-9

Navari-Izzo, F., Pinzino, C., Quartacci, M., F., \& Sgherri, C., L., M. (1999). Superoxide and hydroxyl radical generation, and superoxide dismutase in PS II membrane fragments from wheat. Free Radical Res, 31, S3-9. http://dx.doi.org/10.1080/10715769900301251

Ozkur, O., Ozdemir, F., Bor, M., \& Turkan, I. (2009). Physiochemical and Antioxidant Responses of the Perennial Xerophyte Capparisovata Desf. to Drought. Environ Exp Bot, 66, 487-492. http://dx.doi.org/10.1016/j.envexpbot.2009.04.003

Pelah, D., Shoseyov, O., \& Altman, A. (1995). Characterization of BspA, a major boiling stable water stress responsive protein in aspen (Populus tremula). Tree Physiol, 15, 673-678. http://dx.doi.org/10.1093/treephys/15.10.673

Pinheiro, C., Passarinho, J., A., \& Ricardo, C., P. (2004). Effect of drought and re-watering on metabolism of Lupinus albus organs. Plant Physiol, 124, 17-20.

Sambrook, J., Fritsch, E., F., \& Maniatis, T. (1989). Molecular cloning: a laboratory manual, pp 18.64-18.75. New York: Cold Spring Harbour Laboratory Press.

Sharma, A., D., Rakhra, G., \& Singh, J. (2012). Expression analysis of BsAPase14 acid phosphatase, a stress responsive boiling-stable protein from Triticum aestivum. J Crop Sci Biotech, 15, 41-45. http://dx.doi.org/10.1007/s12892-011-0054-y

Sharma, A., D., Vasudeva, R., \& Kaur, R. (2006). Expression of a boilingstable protein (BsCyp) in response to heat shock, drought and ABA treatments in Sorghum bicolor. Plant Growth Regulation, 50, 249-254. http://dx.doi.org/10.1007/s10725-006-9134-2

Shigeoka, S., Ishikawa, T., Tamoi, M., Miyagawa, Y., Takeda, T., Yabuta, Y., \& Yoshimura, K. (2002). Regulation and function of ascorbate peroxidase isoenzymes. J Exp Bot, 53, 1305-19. http://dx.doi.org/10.1093/jexbot/53.372.1305

Shinozaki, K., \& Yamaguchi-Shinozaki, K. (2007). Gene networks involved in drought stress response and tolerance. J Exp Bot, 58, 221-227. http://dx.doi.org/10.1093/jxb/erl164

Sidel, P., S. (1986). Software Reviews: Statview, Version 1.0. BrainPower Inc., 24009 Ventura Blvd. Social Science Computer Review, 4, 232-237. http://dx.doi.org/10.1177/089443938600400211

Wang, W., B., Kim, Y., H., Lee, H., S., Kim, K., Y., Deng, X., P. \& Kwak, S., S. (2009). Analysis of antioxidant enzyme activity during germination of alfalfa under salt and drought stress. Plant Physiol Biochem, 47, 570577. http://dx.doi.org/10.1016/j.plaphy.2009.02.009 